\title{
Voltammetric Response of Hydrogen Adsorbates on Platinum in Acid Solutions. A Possible H-Adatom Subsurface State
}

\author{
M.E. Martins ${ }^{a}$, C.F. Zinola ${ }^{b}$, and A.J. Arvia ${ }^{a}$ \\ ${ }^{a}$ Instituto de Investigaciones Fisicoquímicas Teóricas y Aplicadas (INIFTA) Sucursal \\ 4, Casilla de Correo 16 (1900) La Plata, Argentina \\ ${ }^{b}$ Laboratorio de Electroquímica, Facultad de Ciencias, T. Narvaja 1674, P.O. Box \\ 10773 Montevideo, Uruguay
}

Received: June 30, 1996; November 20, 1996

\begin{abstract}
Foram aplicadas rotinas combinadas de potencial, envolvendo varreduras voltamétricas e paradas de potencial, na região dos ad-átomos de hidrogênio sobre eletrodos de Pt, em diferentes soluções ácidas, para produzir um aumento da corrente de pico da eletro-desorção do "terceiro" átomo de hidrogênio que aparece cerca de $0.22 \mathrm{~V} v s$. RHE. Este pico pode ser observado para eletrodos de Pt de diferentes topografias. Aparentemente, a contribuição catódica correspondente aparece numa região de potenciais ligeiramente mais positivos que o potencial limiar da reação de desprendimento de hidrogênio. A diferença entre os potenciais de pico referentes as reações redox conjugadas é consistente com uma apreciável irreversibilidade do processo. A pequena carga envolvida neste par de picos é esperada para estados sub-superficiais e intersticiais dos ad-átomos de hidrogênio sobre Pt. Esse tipo de estrutura tem sido predita por cálculos da química quântica.

Combined potential routines involving voltammetric sweeps and potential holdings covering the $\mathrm{H}$-adatom potential range were applied to $\mathrm{Pt}$ electrodes in different aqueous acid solutions to produce an enhancement of the "third" $\mathrm{H}$-atom electrodesorption current peak at ca. $0.22 \mathrm{~V} v$ s. RHE. This peak can be observed for Pt electrodes of different topographies. Seemingly, the corresponding cathodic current contribution appears in a potential range slightly more positive than the hydrogen evolution reaction threshold potential. The peak potential difference related to the conjugated redox reactions is consistent with an appreciable irreversibility of the process. The small charge involved in this pair of peaks is expected from a subsurface and an interstitial $\mathrm{H}$-adatom state on Pt. This type of structure has been predicted from quantum chemistry calculations.
\end{abstract}

Keywords: platinum electrodes, hydrogen evolution, $H$-adatoms, third H-adatom current peak

\section{Introduction}

The hydrogen evolution reaction (HER), one of the most important processes in electrocatalysis, has been used as a prototype for several electrode reactions ${ }^{1-7}$. Depending on the nature of the metal/solution interface, the kinetics of the HER has been explained through different reaction pathways involving the participation of $\mathrm{H}$-adatoms as reaction intermediates. Accordingly, depending on the type of adsorption isotherm which $\mathrm{H}$-adatoms obey, kinetic equations derived from different reaction pathways account for specific potential and time dependencies of $\theta$, the degree of electrode surface coverage by reaction intermediates ${ }^{1-3}$.

However, in conventional mechanistic approaches to the HER under steady-state conditions, little attention has been paid to the influence of the characteristics of adsorption sites on the kinetics of the reaction. In fact, as far as we know, there is only one example in which the possibility of the surface diffusion of $\mathrm{H}$-adatoms occupying different adsorption sites of $\mathrm{Pt}$ has been considered ${ }^{8}$. Since most of the work done at the metal/aqueous solution interface has focused on the evaluation of the isotherm for $\mathrm{H}$-adatoms and 
chemisorption energy ${ }^{2,3,7-10}$, non-equilibrium effects due to surface diffusion processes have been disregarded.

Valuable information about the mechanism of the $H E R$ has been obtained from the underpotential deposition of $\mathrm{H}$-adatoms at noble and semi-noble metals, but little has been gained from those species which might act as actual precursors to $\mathrm{H}_{2}$ molecule formation at overpotential conditions ${ }^{11-14}$. This drawback is caused by the fact that the steady $\mathrm{H}_{2}$ evolution current greatly exceeds those transient current contributions associated with $\mathrm{H}$-adatom reactions. In fact, $A C$ impedance spectroscopy data have made the analysis of $\mathrm{H}$ intermediates possible in a potential range close to the $H E R$ threshold potential ${ }^{15,16}$.

On the other hand, the application of different potential routines to noble metal electrodes produces changes in the surface morphology, including crystallographic orientation ${ }^{17-19}$. These changes involve modifications in the adsorbate characteristics of the metal electrode, as has been well established for $\mathrm{H}$-adatoms on $\mathrm{Pt}^{19}$. In this case, the $\mathrm{H}$-adatom electrosorption voltammogram acts as a sort of fingerprint of the adsorption energy characteristics of the electrode surface, thus offering the possibility of determining the influence of a specific metal topography on a particular reaction, as in the case of the $\mathrm{H}$-adatom electrosorption reaction on Pt substrates.

This paper provides experimental data on the possible existence of a $\mathrm{H}$-adatom state acting as a precursor in the $H E R$, yielding species which appear to be closely related to the so-called "third" anodic voltammetric peak for Pt in acid solutions. In situ infrared data ${ }^{20}$ and visible-infrared sum frequency generation vibrational spectroscopy ${ }^{21,22}$ indicated the presence of these species, which was supported by quantum chemistry calculations ${ }^{23}$.

\section{Experimental}

Electrochemical runs were made in different conventional electrochemical cells made of either glass or Teflon, with a Pt working electrode, a large Pt gauze counterelectrode, and a reversible hydrogen reference electrode. The following aqueous solutions were employed: $x \mathrm{M} \mathrm{H}_{2} \mathrm{SO}_{4}$ $(0.05 \leq \mathrm{x} \leq 1.0), 0.5 \mathrm{M} \mathrm{HClO}_{4}, 0.3 \mathrm{M} \mathrm{HF}$, and $1 \mathrm{M} \mathrm{HF}$. Solutions were prepared from a.r. chemicals and Millipore-MilliQ* water. All runs were performed under continuous oxygen-free nitrogen saturation at $25^{\circ} \mathrm{C}$. Potentials in the text are given in the reversible hydrogen electrode $(R H E)$ scale.

Three types of Pt working electrodes were used.

i) Smooth polycrystalline $(p c)$ Pt electrodes, which were first immersed in a hot $\mathrm{H}_{2} \mathrm{SO}_{4}-\mathrm{HNO}_{3}$ 1:1 mixture, subsequently rinsed with Millipore-MilliQ* water, and finally placed in the working solution.

ii) Smooth $p c$ Pt electrodes, which were subjected to repetitive triangular potential cycling (routine I) at $0.1 \mathrm{~V} \mathrm{~s}^{-1}$ between $\mathrm{E}_{\mathrm{sc}}=0.05 \mathrm{~V}$ and $\mathrm{E}_{\mathrm{sa}}=1.45 \mathrm{~V}$ until a stable voltammogram (blank) was achieved. They were then subjected to preset repetitive symmetric square wave potential cycling (routine II) to develop a certain preferred crystallographic orientation $(p c o)$. This potential routine was characterized by an upper $\left(\mathrm{E}_{\mathrm{u}}\right)$ and a lower switching potential $\left(\mathrm{E}_{\mathrm{l}}\right)$ and a frequency (f). Details of these techniques have been given elsewhere $^{17-19}$. Two types of pco Pt electrodes (pco I and pco II) were employed. The preparation conditions under routine II were $-0.2 \mathrm{~V} \leq \mathrm{E}_{\mathrm{l}} \leq 0.05 \mathrm{~V}, \mathrm{E}_{\mathrm{u}}=1.5 \mathrm{~V}, 4 \mathrm{kHz} \leq \mathrm{f} \leq$ $7 \mathrm{kHz}$ for $120 \mathrm{~s} \leq \mathrm{t} \leq 3600 \mathrm{~s}$ for $p c o \mathrm{IPt}$, and $0.60 \leq \mathrm{E}_{1} \leq 0.70$ $\mathrm{V}, \mathrm{E}_{\mathrm{u}}=1.5 \mathrm{~V}, 4 \mathrm{kHz} \leq \mathrm{f} \leq 7 \mathrm{kHz}$ for $120 \mathrm{~s} \leq \mathrm{t} \leq 3600 \mathrm{~s}$ for pco II Pt. The cyclicvoltammogram of pco I Pt run in $1 \mathrm{M}$ $\mathrm{H}_{2} \mathrm{SO}_{4}$ at $0.1 \mathrm{~V} \mathrm{~s}^{-1}$ was similar to that of a $\mathrm{Pt}(100)$ surface after it has been cycled a few times through the O-adatom potential region ${ }^{24-26}$. However, in contrast to previous results $^{18}$, the electroreduction sweep for pco I Pt exhibited a current hump very near the HER threshold potential where the Pt surface was almost completely covered by $\mathrm{H}$-adatoms. On the other hand, the cyclicvoltammograms of pco II Pt closely resembled the characteristics described in the literature for $\mathrm{Pt}(111)$ after it has been potential cycled in the $\mathrm{O}$-adatom potential range ${ }^{27}$.

iii) Columnar structured $(c s)$ Pt electrodes involving roughness factors in the range of 10 to 150 . The preparation technique of this type of electrode has been described elsewhere ${ }^{28}$. Voltammograms obtained for $c s$ Pt electrodes in $1 \mathrm{M} \mathrm{H}_{2} \mathrm{SO}_{4}$ showed the same pair of conjugated current peaks for the strongly and weakly bound $\mathrm{H}$-adatoms.

A combined cyclic voltammetry technique was employed to follow the various $\mathrm{H}$-adatom electrosorption processes. The first step consisted of the application of a repetitive triangular potential sweep covering the range $\mathrm{E}_{\mathrm{sc}}=0.02 \mathrm{~V}$ to $0.05 \mathrm{~V} \leq \mathrm{E}_{\mathrm{sa}} \leq 0.25 \mathrm{~V}$ (routine III), and the second step involved the application of triangular potential sweeps, including a potential holding at $\mathrm{E}_{\mathrm{h}}\left(0.02 \mathrm{~V} \leq \mathrm{E}_{\mathrm{h}} \leq 0.25 \mathrm{~V}\right)$ in the potential sweep run in the negative potential direction, for time $t_{h}\left(10 s \leq t_{h} \leq 20 \mathrm{~min}\right)$ (routine IV). Both routines III and IV were followed by cyclicvoltammetry run in the range from $\mathrm{E}_{\mathrm{sc}}=0.05 \mathrm{~V}$ to either $\mathrm{E}_{\mathrm{sa}}=0.50 \mathrm{~V}$ or $1.45 \mathrm{~V}$. Changes in the successive voltammograms allowed us to infer possible rearrangements of the $\mathrm{H}$-adatom configuration on $\mathrm{Pt}$ promoted by the application of the potential routines. Finally, the potential cycling was continued until the stable cyclicvoltammogram was attained. The same routine was applied to all working solutions.

The real surface area of $p c$-Pt, $p c o$-Pt, and $c s$-Pt electrodes was measured through the change of the H-adatom electrosorption read from the voltammogram run at $0.1 \mathrm{~V} \mathrm{~s}^{-1}$, covering the range from $\mathrm{E}_{\mathrm{sc}}=0.05 \mathrm{~V}$ to $\mathrm{E}_{\mathrm{sa}}=0.50$ $\mathrm{V}$ in aqueous $0.5 \mathrm{M} \mathrm{H}_{2} \mathrm{SO}_{4}$. For this purpose, the $\mathrm{H}$-adatom monolayer charge density for each Pt surface was taken 


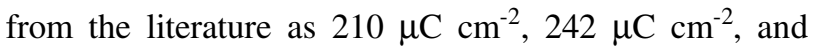
$210 \mu \mathrm{C} \mathrm{cm}{ }^{-2}$ for Pt (100), Pt (111), and $p c$-Pt, respectively ${ }^{29}$.

\section{Results}

\section{General features}

Cyclic voltammograms run at $0.1 \mathrm{~V} \mathrm{~s}^{-1}$ for $p c o$ I-Pt and pco II-Pt in aqueous $0.5 \mathrm{M} \mathrm{H}_{2} \mathrm{SO}_{4}$ and 1 aqueous $\mathrm{M} \mathrm{HF}$ (Fig. 1), as well as those run in aqueous $0.5 \mathrm{M} \mathrm{HClO}_{4}$ in the range of $\mathrm{E}_{\mathrm{sc}}=0.05$ to $\mathrm{E}_{\mathrm{sa}}=1.45 \mathrm{~V}$, exhibit qualitatively comparable features. Thus, the $\mathrm{H}$-adatom electrosorption potential range extends from $0.05 \mathrm{~V}$ to $0.45 \mathrm{~V}$, and the $\mathrm{O}$-atom electrosorption and oxide formation potential range covers from ca. $0.70 \mathrm{~V}$ to $1.50 \mathrm{~V}$. The charging-discharging double layer region is located in between. These results confirm the influence of the Pt surface morphology on the $\mathrm{H}$ - and $\mathrm{O}$-adatom electrosorption voltammograms in those electrolytes.

Voltammograms show that the H-Pt bond is somewhat stronger in aqueous $1 \mathrm{M} \mathrm{HF}$, and that the $\mathrm{H}$-adatom electrodesorption covers a potential range wider than in aqueous $0.5 \mathrm{M} \mathrm{H}_{2} \mathrm{SO}_{4}$. Likewise, it appears that in aqueous $1 \mathrm{M} \mathrm{HF}$ the $\mathrm{O}-\mathrm{Pt}$ bond is stronger, and the $\mathrm{O}_{2}$ evolution threshold potential is lower than in aqueous $0.5 \mathrm{M} \mathrm{H}_{2} \mathrm{SO}_{4}$. Then, the behavior of the $\mathrm{H}$ - and $\mathrm{O}$-atom electrodesorption in aqueous $1 \mathrm{M} \mathrm{HF}$ is rather similar to that found earlier in aqueous $\mathrm{HBF}_{4}$ solution $^{30}$, and can be explained by the low anion adsorbability on Pt in those solutions.

\section{Results obtained using pco Pt electrodes}

$\mathrm{H}$-adatom electrosorption reactions on $p c \mathrm{Pt}$ display a multiplicity of current peaks, which are associated with different $\mathrm{H}$-adatom states, and the relative contribution of these peaks changes according to the electrode surface characteristics. Thus, for $p c o$ I Pt in aqueous $1 \mathrm{M} \mathrm{HF}$, there is a relatively large contribution of those reactions involving strongly bound $\mathrm{H}$-adatoms, the corresponding pair of peaks lying at $0.30 \mathrm{~V}$, a potential which is positively shifted with respect to that observed for the same reactions in aqueous $0.5 \mathrm{M} \mathrm{H}_{2} \mathrm{SO}_{4}$. It should be noted that by setting $\mathrm{E}_{\mathrm{sc}} \cong 0 \mathrm{~V}$, the voltammogram exhibits a new current contribution at $c a .0 .05 \mathrm{~V}$, a potential slightly more positive than the HER threshold potential. This peak decreases progressively with further cycling in the $\mathrm{H}$-adatom potential range, but the conjugated pair of peaks at $c a .0 .3 \mathrm{~V}$ becomes sharper and higher (Fig. 2). The H-adatom electroadsorption charge derived from the first and second voltammogram is greater than that derived from the $\mathrm{H}$-adatom electrodesorption voltammogram, but the anodic to cathodic charge ratio after the third cyclicvoltammogram remains the same. Conversely, when the potential routine $\mathrm{II}$ is applied in the range of $\mathrm{E}_{1}=0.05 \mathrm{~V}$ to $\mathrm{E}_{\mathrm{u}}=1.50 \mathrm{~V}$ with $\mathrm{f}=5 \mathrm{kHz}$, the subsequent voltammogram

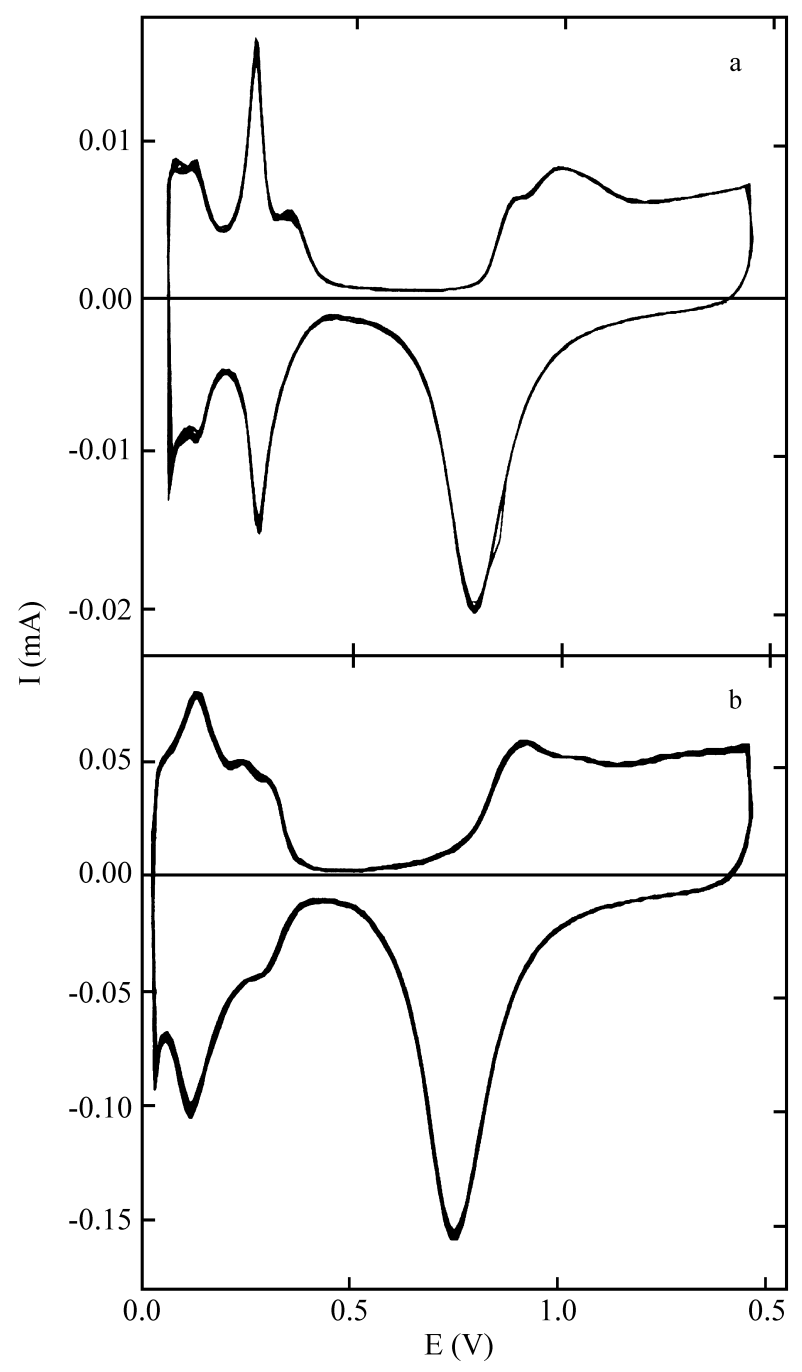

Figure 1. Cyclic voltammograms run at $0.1 \mathrm{~V} \mathrm{~s}^{-1}$ for $p c o$ I and $p c o$ II $\mathrm{Pt}$ electrodes in aqueous (a) $0.5 \mathrm{M} \mathrm{H}_{2} \mathrm{SO}_{4}$ and aqueous (b) $1 \mathrm{MHF} .25^{\circ} \mathrm{C}$.

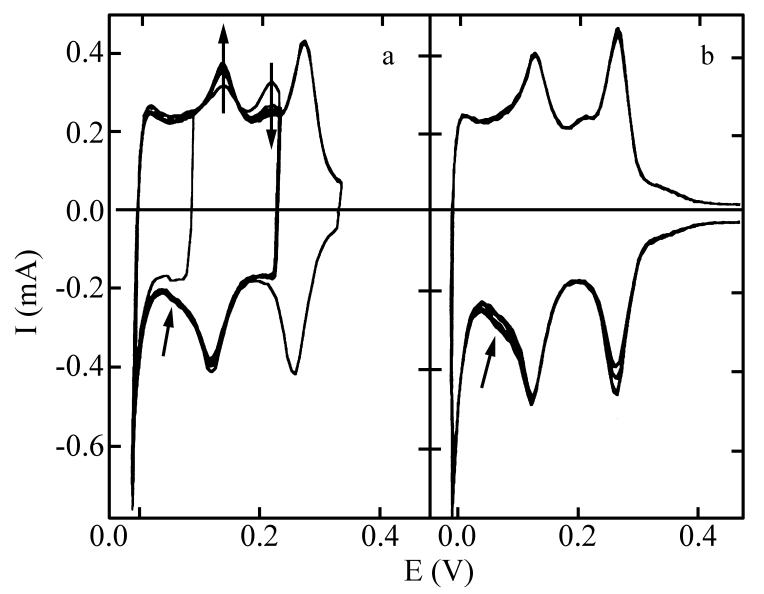

Figure 2. Cyclic voltammograms run at $0.05 \mathrm{~V} \mathrm{~s}^{-1}$ for $p c o$ I Pt electrodes in aqueous $0.5 \mathrm{M} \mathrm{H}_{2} \mathrm{SO}_{4}$ after applying routine III. $25^{\circ} \mathrm{C}$. Arrows indicate the direction of the change in the voltammetric peaks on the potential cycling. The small arrows show the small cathodic voltammetric contribution related to the "third" anodic current peak. 
shows that the cathodic hump at $0.05 \mathrm{~V}$ disappears, and then the anodic to cathodic charge ratio remains close to 1 , irrespective of the number of cycles.

Cyclic voltammograms of pco II Pt in aqueous $1 \mathrm{M} \mathrm{HF}$ and aqueous $1 \mathrm{M} \mathrm{H}_{2} \mathrm{SO}_{4}$ show a relatively large contribution of weakly bound $\mathrm{H}$-adatoms as a pair of reversible peaks at $0.12 \mathrm{~V}$ and $0.10 \mathrm{~V}$, respectively (Fig. 3). In this case, both $\mathrm{H}-$ and $\mathrm{O}$-adatom electroadsorption are delayed as the electrolyte concentration is increased, due to the appearance of the specific influence of anion adsorption ${ }^{31}$. Otherwise, by setting $E_{1}$ in the range $0.40 \leq E_{1} \leq 0.50 \mathrm{~V}$, the voltammogram shows a cathodic hump at $c a .0 .05 \mathrm{~V}$, which continues to be observed in the second scan, but disappears later on. This change is accompanied by a sharpness of the pair of peaks found at $0.12 \mathrm{~V}$. Afterwards, the stable voltammogram run in the $\mathrm{H}$-adatom potential regi-

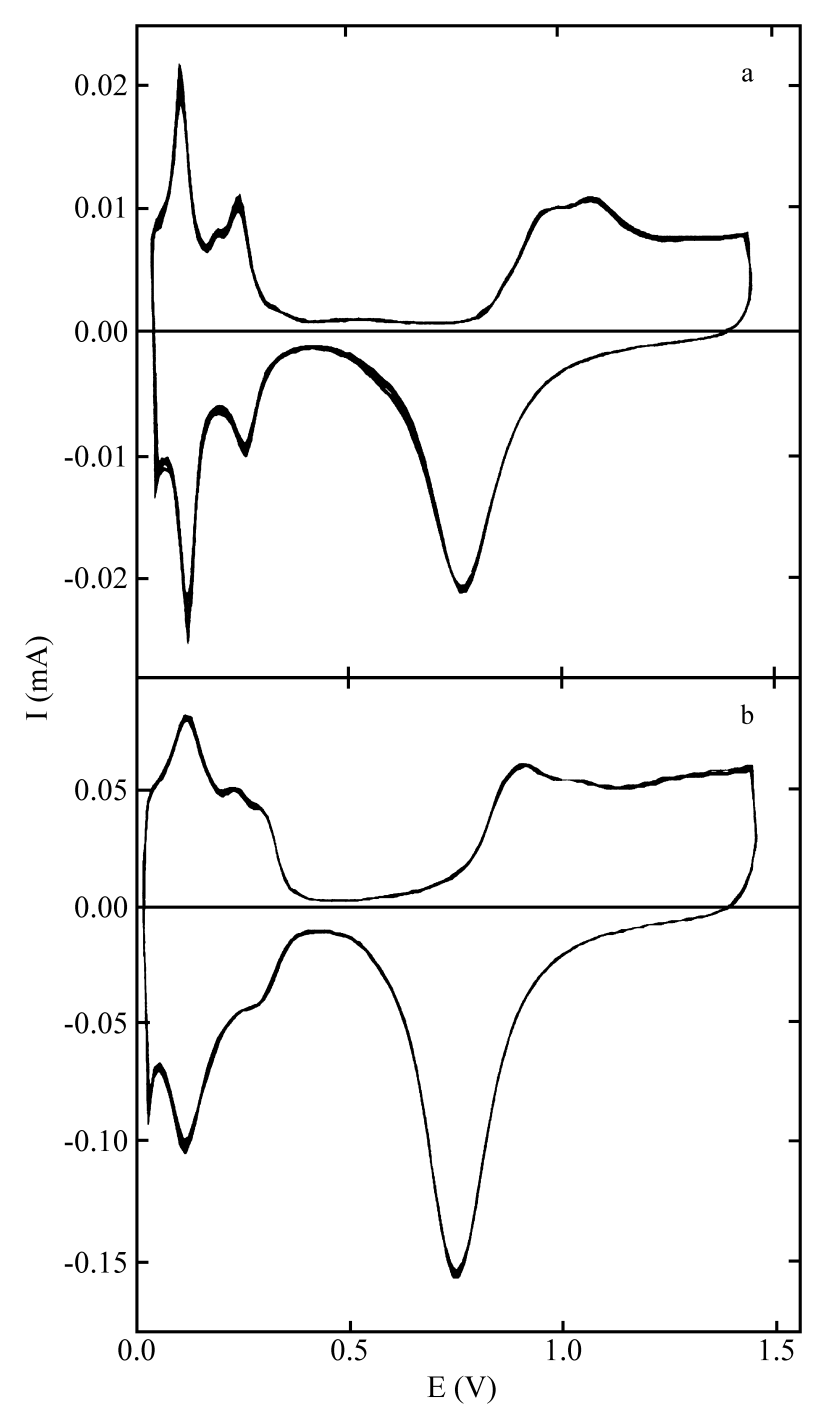

Figure 3. Cyclic voltammograms run at $0.1 \mathrm{~V} \mathrm{~s}^{-1}$ for $p c o$ II Pt electrodes in (a) aqueous $1 \mathrm{M} \mathrm{H}_{2} \mathrm{SO}_{4}$ and (b) aqueous $1 \mathrm{M} \mathrm{HF} .25^{\circ} \mathrm{C}$. on shows again that the anodic to cathodic charge ratio becomes equal to one.

The voltammetric resolution of the "third" anodic peak also depends on the potential sweep rate. For scan rates above $0.5 \mathrm{~V} \mathrm{~s}^{-1}$, no contribution of this peak can be observed. However, holding the potential at $\mathrm{E}_{\mathrm{h}}=0.064 \mathrm{~V}$ (routine IV) it results in a clear definition of the "third" anodic peak, although it largely overlaps the strongly bound $\mathrm{H}$-adatom electro oxidation current peak. These results confirm that the kinetics of those reactions involved in the "third" anodic peak is rather slow, as has been previously concluded by other authors ${ }^{27,32}$.

Voltammetric runs were also made with pco II Pt in aqueous $1 \mathrm{M} \mathrm{H}_{2} \mathrm{SO}_{4}$ applying routine IV in the potential range of $0.052 \mathrm{~V} \leq \mathrm{E}_{\mathrm{h}} \leq 0.123 \mathrm{~V}$. The voltammetric features resulting from these electrodes are similar to those already described for $c s$ Pt. The optimal enhancement of the "third"

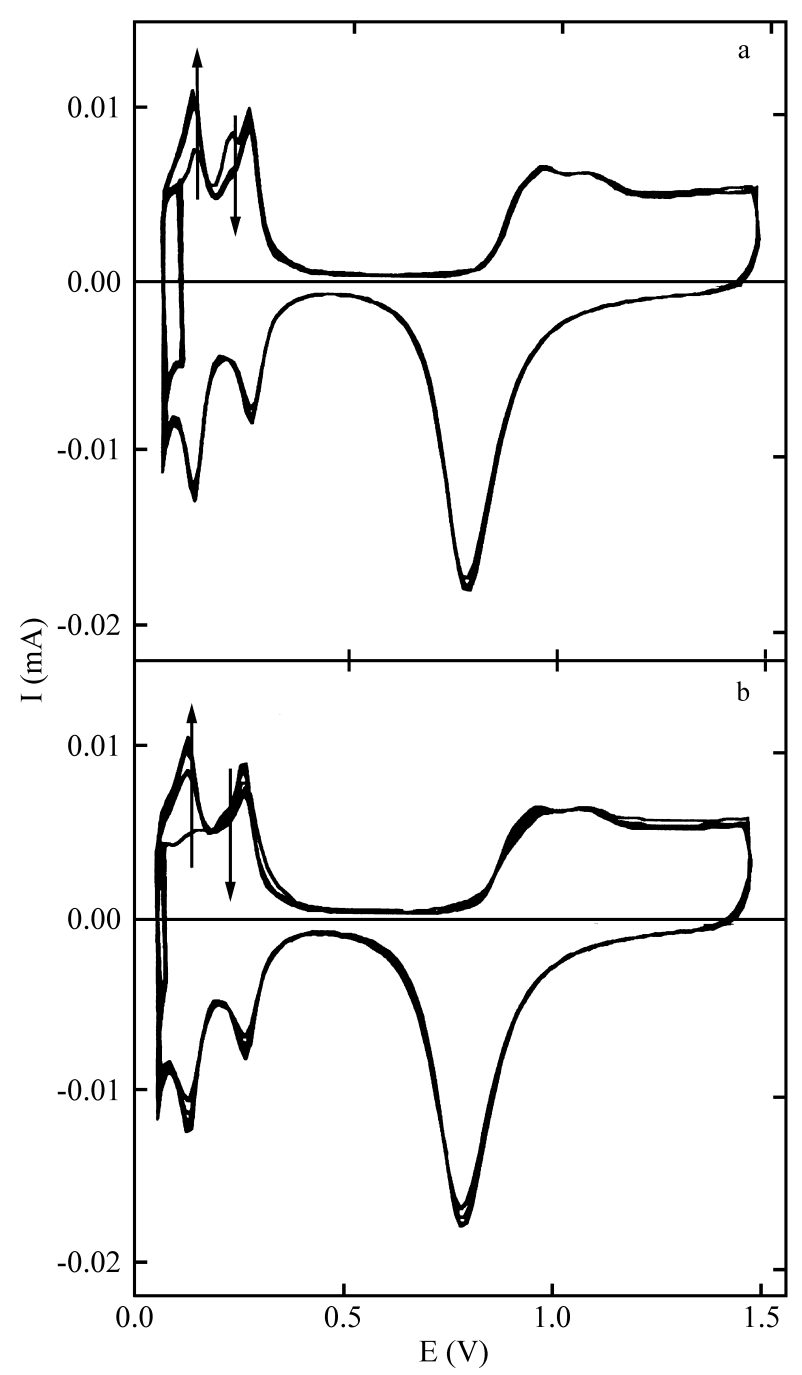

Figure 4. Cyclic voltammograms run at $0.1 \mathrm{~V} \mathrm{~s}^{-1}$ for $p c o$ I Pt electrodes in aqueous $1 \mathrm{M} \mathrm{H}_{2} \mathrm{SO}_{4}$ after applying routine III. (a) $\mathrm{t}_{\mathrm{h}}=3 \mathrm{~min}$; (b) $\mathrm{t}_{\mathrm{h}}=25 \min .25^{\circ} \mathrm{C}$. 
anodic peak appears at $E_{h}=0.049 \mathrm{~V}$. (Fig. 4). However, for potential holdings exceeding $30 \mathrm{~min}$, a strong inhibition of both the weakly bound $\mathrm{H}$-adatom electrosorption peak and the "third" anodic peak, as well as a significant increase in the strongly bound $\mathrm{H}$-adatom desorption peak followed by the typical hump already described for $p c o$ II Pt at $0.35 \mathrm{~V}^{18}$ can be seen. These results can be explained by the likely surface diffusion of $\mathrm{H}$-adatoms on different crystallographic sites ${ }^{8}$.

Following the $\mathrm{H}$-adatom voltammetric fingerprints on Pt single crystals ${ }^{24-26}$, it appears that for short potential holding times, the $\mathrm{H}$-adatom species diffuses from the (111) to (110) sites, i.e., the "third" anodic peak enhancement is favored (Fig. 4a). However it appears that longer potential holding times at $\mathrm{E}_{\mathrm{h}}=0.05 \mathrm{~V}$ in aqueous $0.5 \mathrm{M} \mathrm{H}_{2} \mathrm{SO}_{4}$ would favor the $\mathrm{H}$-adatom surface diffusion to (100) sites (Fig. 4b), resulting in the appearance of the cathodic shoulder near the HER.

The above results, together with those obtained applying routine III between $\mathrm{E}_{\mathrm{sc}}=0 \mathrm{~V}$ and $\mathrm{E}_{\mathrm{sa}}=0.05 \mathrm{~V}$, give a further insight into the nature of the cathodic contribution related to the "third" anodic peak, although the time required for achieving the same effect for routine III is much shorter than that for routine IV (Fig. 5).

\section{Results obtained using cs Pt electrodes}

The application of routine III to a cs Pt in aqueous $0.5 \mathrm{M}$ $\mathrm{H}_{2} \mathrm{SO}_{4}$ within the $\mathrm{H}$-adatom potential range, followed by a sequence of triangular potential sweeps of increasing $\mathrm{E}_{\mathrm{sa}}$, produces clear and specific voltammetric features related to both the strongly and weakly bound $\mathrm{H}$-adatoms, as well as to the "third" anodic peak and its conjugated contribution. Thus, a potential cycling between $\mathrm{E}_{\mathrm{sc}}=0 \mathrm{~V}$ and $\mathrm{E}_{\mathrm{sa}}=0.055 \mathrm{~V}$ at $0.05 \mathrm{~V} \mathrm{~s}^{-1}$ both enhances the "third" anodic peak and decreases the desorption peak of weakly bound $\mathrm{H}$-adatoms, as can be seen during the first subsequent electrooxidation potential sweep (Fig. 6a, b). Whenever the potential cycling is followed by a gradual increase in $\mathrm{E}_{\mathrm{sa}}$ within the double layer potential range, keeping $\mathrm{E}_{\mathrm{sc}}$ constant (Fig. 6c), a well-defined strongly bound $\mathrm{H}$-adatom reversible pair of peaks with a constant peak height can be observed. Otherwise, for Esa>0.8 V, i.e., when the incipient $\mathrm{O}$-atom electroadsorption potential range is covered, the contribution of the pair of reversible peaks increases, whereas that of the "third" anodic peak turns out to be very small (Fig. 6d). Furthermore, when Esa $>1.0 \mathrm{~V}$, a decrease in the height of the strongly bound $\mathrm{H}$-adatom pair of peaks, and an increase in height of the "third" anodic peak can be seen (Fig. 6e), as has already been observed for Pt (110) subsequent to a potential excursion in the oxygen atom electroadsorption-electrodesorption range ${ }^{32}$. Likewise, for Esa $>1.2 \mathrm{~V}$, the height of the weakly bound $\mathrm{H}$-adatom anodic contribution becomes almost constant. Furthermore, a progressive increase in the current contribution on the cat-

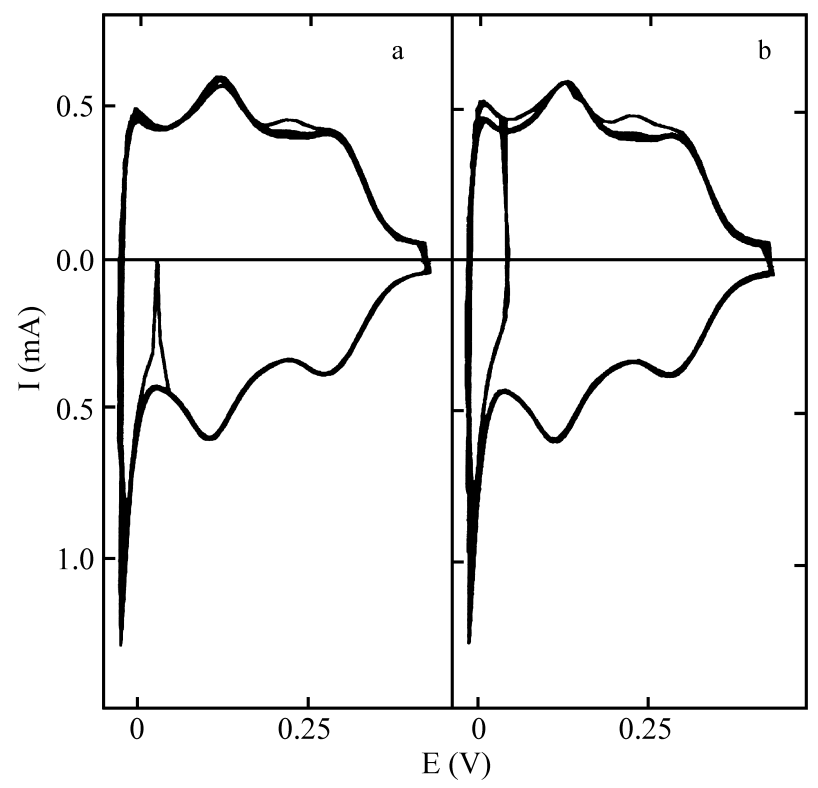

Figure 5. Cyclic voltammograms run at $0.1 \mathrm{~V} \mathrm{~s}^{-1}$ for $p c o$ I Pt electrodes in aqueous $0.5 \mathrm{M} \mathrm{HClO}_{4}$ after applying routine IV for (a) $t_{\mathrm{h}}=300$ $\mathrm{s}$, and routine III (b) for $\mathrm{t}_{\mathrm{h}}=140 \mathrm{~s} . \mathrm{E}_{\mathrm{h}}=0.03 \mathrm{~V} .25^{\circ} \mathrm{C}$.

hodic branch of the weakly bound electroreduction peak, as well as that in the "third" anodic peak, can be observed. The best definition of the "third" anodic peak is observed under routine III for lower potential sweep rates.

Qualitatively similar results were obtained for aqueous $1 \mathrm{M} \mathrm{HF}$ and aqueous $0.5 \mathrm{M} \mathrm{HClO}_{4}$, although in these cases a weaker voltammetric response of the "third" anodic peak was found. These effects are no longer observed when routine III is applied at $\mathrm{E}_{\mathrm{sa}}>0.15 \mathrm{~V}$. However, the influence of the nature and the concentration of anions on the development of the "third" anodic peak deserves further study.

On the other hand, routine IV produces different voltammetric contributions, depending on the potential holding and time spent. Thus, longer times and lower potential holding values enhance the contribution of the "third" anodic peak. However, a limiting time to attain the effect found at each potential holding that depends on the acid solution composition.

The comparison of data derived from the application of either routine III or IV to $c s \mathrm{Pt}$ in the acid aqueous solutions shows that in the former case, the greatest enhancement and definition of the "third" anodic peak was achieved. It should be noted, however, that the "third" peak for $c s \mathrm{Pt}$ is more poorly defined in aqueous $\mathrm{HF}$ and $\mathrm{HClO}_{4}$ than in aqueous $\mathrm{H}_{2} \mathrm{SO}_{4}$ solution.

\section{Discussion}

\section{Description of possible H-adatom states}

It is well known that $\mathrm{H}$-atom electrosorption on Pt results mainly in the formation of two different adsorbates, 
which correspond to the weakly and strongly bound adsorbed H-atom. For Pt(111) single crystal, the weak H-Pt bonding, in contrast to the strong $\mathrm{H}-\mathrm{Pt}$ bonding for $\mathrm{Pt}(100)$, should involve the contribution of a water molecule in the formation of the adsorbed ensemble ${ }^{33-37}$, which can be formally represented as a $\left[\mathrm{Pt}_{\mathrm{N}} . \mathrm{H} . \mathrm{OH}_{2}\right]$ ensemble, where $\mathrm{N}$ represents the number of $\mathrm{Pt}$ atoms involved. In fact, depending on whether the electron energy level is lower or higher than the Pt Fermi level, either negatively or positi- vely charged $\mathrm{H}$-adatoms result. This excess of charge results in a change in the shape of the potential energy curves, which in turn implies a variation in both the H-Pt site interaction for each possible $\mathrm{H}$-adatom coordination, and the polarization of molecules at the interface. IR spectroscopy data show that the bond energy of weakly bound $\mathrm{H}$-adatoms on $\mathrm{Pt}(111)$ depends on the applied electric potential, i.e., on the charge density on the metal ${ }^{14,34}$. Otherwise, strongly bound $\mathrm{H}$-adatoms on $\mathrm{Pt}$ (100) imply an

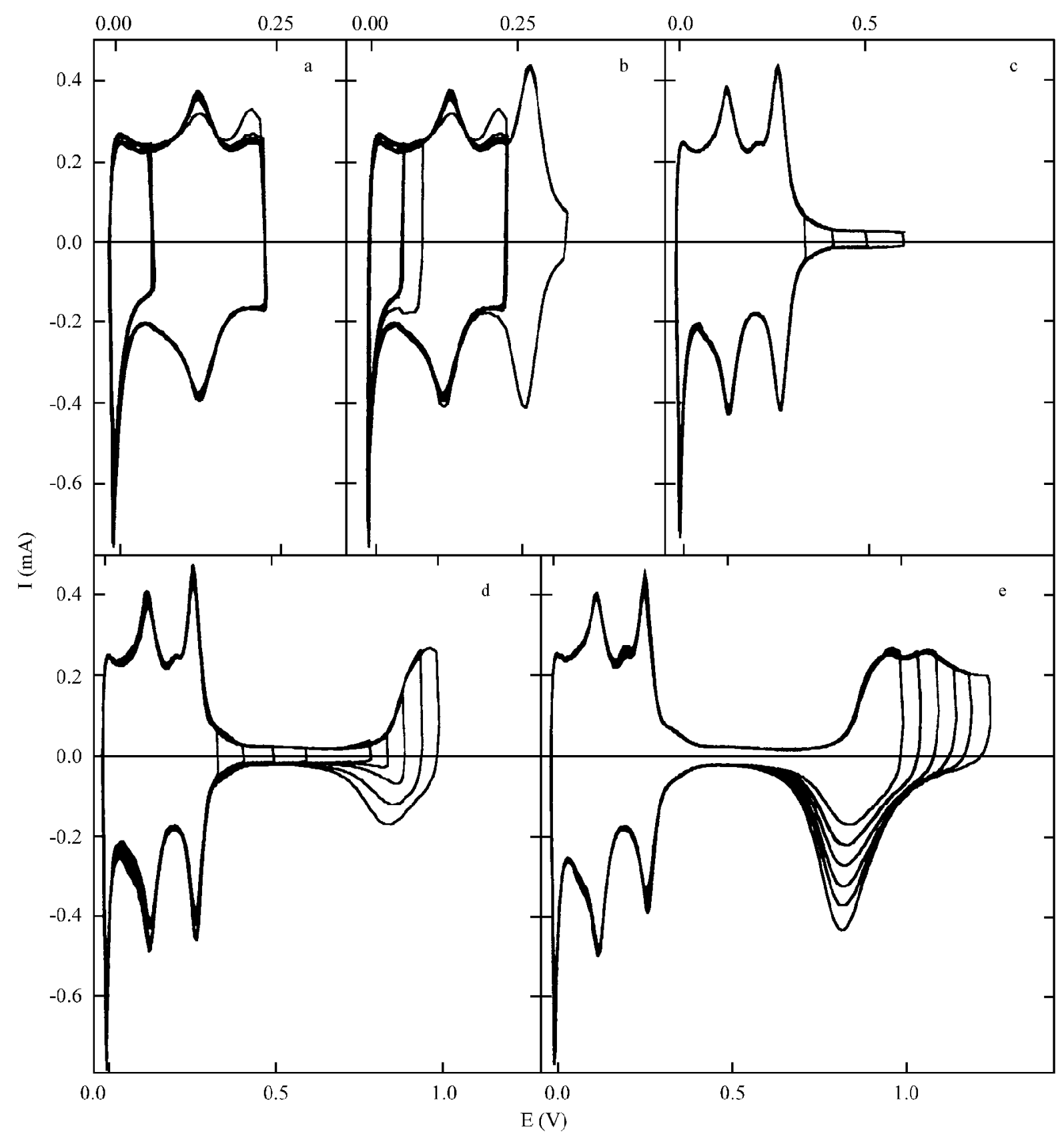

Figure 6. Cyclic voltammograms run at $0.05 \mathrm{~V} \mathrm{~s}^{-1}$ on $c s$ Pt electrodes in aqueous $1 \mathrm{M} \mathrm{H}_{2} \mathrm{SO}_{4}$ after applying routine III for $\mathrm{t}_{\mathrm{h}}=3 \mathrm{~min}$ and followed by cyclicvoltammetry with $\mathrm{E}_{\mathrm{sc}}=0.02 \mathrm{~V}$ and a gradual increase of $\mathrm{E}_{\mathrm{sa}}$. (a) $\mathrm{E}_{\mathrm{sa}}=0.23 \mathrm{~V}$; (b) $\mathrm{E}_{\mathrm{sa}}=0.33 \mathrm{~V}$; (c) $\mathrm{E}_{\mathrm{sa}}=0.60 \mathrm{~V}$; (d) $\mathrm{E}_{\mathrm{sa}}=1.0 \mathrm{~V}$; (e) $\mathrm{E}_{\mathrm{sa}}=1.25$ V. $25^{\circ} \mathrm{C}$. 
adsorbed ensemble in which the $\mathrm{H}$-atom density is delocalized on the Pt surface ${ }^{33}$.

Recent results ${ }^{23}$ have shown that the formation of $\mathrm{H}$-adsorbates at surface $\mathrm{Pt}$ sites and subsurface $\mathrm{Pt}$ sites in the simulated aqueous electrochemical environment is possible on both $\mathrm{Pt}(111)$ and $\mathrm{Pt}(100)$ clusters. These results predict that a transition from a surface to a subsurface adsorbate configuration was feasible by adequately changing the applied electric potential, thus providing a new insight into the nature of $\mathrm{H}$-adatom species on $\mathrm{Pt}$ in both vacuum and aqueous environments. This type of configurational transition has been reported for $\operatorname{Pd}(111)^{38}$, and the presence of subsurface $\mathrm{H}$-adatom states at $\mathrm{Pt}, \mathrm{Pd}$, and $\mathrm{Ni}$ single crystal electrodes as well ${ }^{39,40}$.

It has been proven that $\mathrm{H}$-adatom subsurface states on Pt result from $\mathrm{H}$-adatom stabilization by an excess of negative surface charge which favors a transition from a $\mathrm{H}$-adatom bridge coordination to a $\mathrm{H}$-adatom hollow subsurface coordination on $\mathrm{Pt}(100)$, and from a $\mathrm{H}$-adatom (3-1) hollow coordination to a H-adatom hollow subsurface coordination on $\mathrm{Pt}(111)$. Accordingly, H-adatoms bound to a surface Pt and a subsurface Pt atom are electronically different as a result of the excess of negative charge at the $\mathrm{H}$-adatom bound to a subsurface Pt atom. The possible existence of $\mathrm{H}$-adatoms at the subsurface level would then increase the number of electrochemical reactions in which $\mathrm{H}$-atom states on $\mathrm{Pt}$ are involved.

\section{Interpretation of experimental data}

The fact that the enhancement of the "third" H-atom electrodesorption peak at $c a$. $0.22 \mathrm{~V}$ occurs when the potential routine involving either routine (III) or routine (IV) is applied in the range $0.02 \mathrm{~V} \leq \mathrm{E} \leq 0.15 \mathrm{~V}$ suggests that the "third" anodic peak must result from species produced in the cathodic process which takes place in the potential range between the weakly bound $\mathrm{H}$-atom electrosorption peak and the HER threshold potential. This means that the $\mathrm{H}$-adatom subsurface state is produced in the potential range where the cathodic current hump appears, i.e., at ca. 0.05 V.

In addition, the results show two kinetically relevant facts, namely, the potential difference between the "third" anodic peak and that of its conjugated cathodic contribution, and the potential shift of the "third" anodic peak in the positive direction for increasing potential sweep rates. In principle, these facts are consistent with the irreversibility of the overall process involving subsurface $\mathrm{H}$-adatom, probably because the species involved in the cathodic and anodic reactions are not exactly the same, a situation which might arise from a change in the configuration of the surface species produced cathodically. Hence, the behavior of the conjugated processes related to the "third" anodic peak contrasts with the reversibility exhibited by both the strongly and weakly bound $\mathrm{H}$-adatom conjugated pair of peaks, whose peak potentials are independent of the potential sweep rate used in conventional voltammetry in the absence of ohmic polarization.

The H-Pt subsurface state is enhanced by either routine III or routine IV, as demonstrated above by an anodic potential sweep following these routines. Consequently, the contribution of the subsurface state and the "third" enhanced anodic peak depends strongly on the potential holding value and its duration, and it gradually disappears when the potential cycling is performed from $\mathrm{E}_{\mathrm{sc}}=0.02 \mathrm{~V}$ to $\mathrm{E}_{\mathrm{sa}}=$ $0.50 \mathrm{~V}$. Then, the intermediate $\mathrm{H}$-adatom state is largely consumed by reaction (1) (Fig. 7), and practically no subsurface $\mathrm{H}$-adatom state can be observed in the anodic voltammetric sweep.

If one considers that the cathodically formed adsorbed species which are responsible for the "third" anodic peak appear for a $\mathrm{H} / \mathrm{Pt}$ ratio equal to $1(\theta \otimes 1)$, it is still possible to incorporate additional $\mathrm{H}$-atoms at interstitial positions leading to intermediate adsorbed species, as shown in Fig. 7. This species, acting as a precursor to the HER, has a low stability, and therefore, the corresponding value of $\theta$ results in only a small fraction of the H-adatom monolayer. The latter situation has been confirmed by the analysis of the corresponding voltammetric charges. The intermediate adsorbed species could probably be related to the origin of the $\mathrm{Pt}-\mathrm{H}$ vibration frequency recorded near $0.05 \mathrm{~V}$ by electrochemically modulated infrared spectroscopy ${ }^{20}$ and visible-infrared sum frequency generation vibrational spectroscopy $^{21,22}$.

The decomposition of the new intermediate would result in the formation of $\mathrm{H}_{2}$ molecule and a $\mathrm{Pt}$ surface covered by a $\mathrm{H}$-adatom monolayer, as indicated by reaction 1 (Fig. 7). On the other hand, under adequate potential perturbation conditions, the new intermediate state may reorganize itself, leading to a more stable configuration

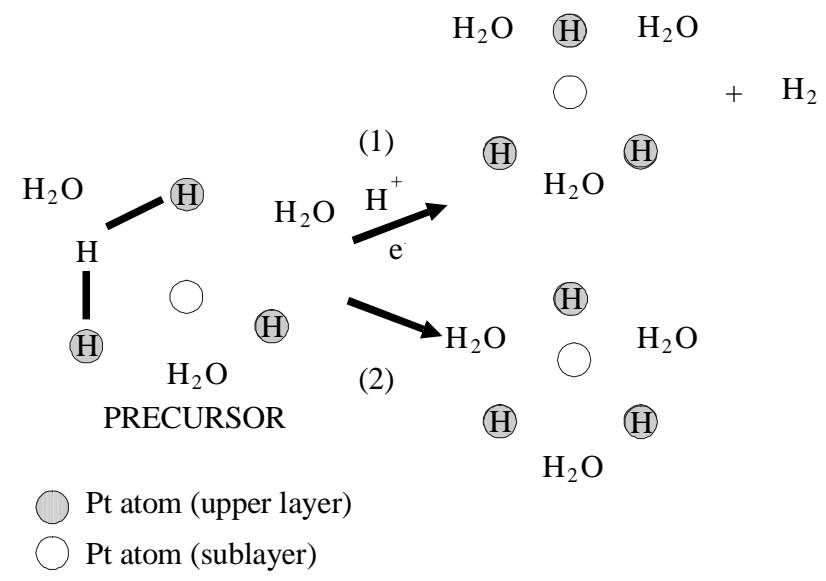

Figure 7. Reaction scheme for the formation of both interstitial $\mathrm{H}$-adatom and subsurface $\mathrm{H}$-adatom states on a $\mathrm{Pt}(111)$ face. 
involving a stronger interaction between the $\mathrm{H}$ atom at the interstitial position and $\mathrm{Pt}$ atoms at the subsurface level. The H-adatom at the subsurface level appears to be electrooxidized at a higher potential, and would be responsible for the existence of the "third" anodic peak.

Finally, the weaker response of the "third" anodic peak on $c s$ Pt derives from the typical response of columnar-structured electrodes that, in this case, makes the HER proceed mainly at the tips of columns ${ }^{28}$, leaving a rather restricted fraction for the formation of the HER precursor.

\section{Acknowledgments}

This work was financially supported by CONICET (Consejo Nacional de Investigaciones Científicas y Técnicas) and CIC (Centro de Investigaciones Científicas) de la Pcia. de Bs. As. Argentina. CFZ thanks TWAS (Third World Academy of Sciences) and CSIC (Comisión Sectorial de Investigaciones Científicas), Uruguay for the projects granted.

\section{References}

1. Frumkin, A. In Advances in Electrochemistry and Electrochemical Engineering; Delahay, P.; Tobias, C., Eds.; New York, 1963, Vol. 3, Interscience.

2. Parsons, R. Trans. Faraday Soc. 1958, 54, 1053.

3. Gerischer, H. Z. Physik. Chem. 1956, 8, 137.

4. Conway, B.E.; Bockris, J.O’M. J. Chem. Phys. 1957, 26, 532.

5. Horiuti, J.; Polanyi, M. Acta Physicochim. U.R.S.S. 1935, 2, 505.

6. Bockris, J.O'M. In Modern Aspects of Electrochemistry; Bockris, J.O’M., Ed.; Butterworths, London, 1954, Vol. 1, Chap. 4.

7. Conway, B.E.; Bai, L. Electrochim. Acta 1986, 31, 1013.

8. Yeager, E.B.; O’Gready, W.; Woo, M.Y.C.; Hagans, P. J. Electrochem. Soc. 1978, 125, 1348.

9. Tilak, B.V.; Conway, B.E. Electrochim. Acta 1976, 21,745 .

10. Tilak, B.V.; Rader, C.G.; Conway, B.E. Electrochim. Acta 1977, 22, 1167.

11. Harrington, D.A.; Conway, B.E. J. Electroanal. Chem. 1987, 221, 1.

12. Gao, L.; Conway, B.E. Electrochim. Acta 1994, 39, 1681.

13. Torresi, R.M.; Camara, O.R.; Pauli, C.P. de; Giordano, M.C. Electrochim. Acta 1987, 32, 1301.

14. Breiter, M.W. J. Electroanal. Chem. 1978, 90, 425.

15. Gerischer, H.; Mehl, W. Z. Elektrochem. 1955, 59, 1049.

16. Breiter, M.; Kammermaier, H.; Knorr, C.A. Z. Elektrochem. 1956, 60, 37.
17. Visintín, A.; Canullo, J.C.; Triaca, W.E.; Arvia, A.J. J. Electroanal. Chem. 1988, 239, 67.

18. Triaca, W.E.; Kessler, T.; Canullo, J.C.; Arvia, A.J. J. Electrochem. Soc. 1987, 134, 1165.

19. Chialvo, A.C.; Triaca, W.E.; Arvia, A.J. J. Electroanal. Chem. 1983, 146, 93.

20. Nichols, R.J.; Bewick, A. J. Electroanal. Chem. 1986, 202, 101.

21. Tadjeddine, A.; Peremans, A. Abstract from Surf. Sci. and Electrochemistry IUVSTA `94, p. 40 (L 24) San Benedetto del Tronto, 12-16 September, Italy, 1994.

22. Tadjeddine, A.; Peremans, A.; Guyot-Sionnest, P. Surf. Sci. 1995, 335, 210.

23. Zinola, C.F.; Arvia, A.J. Electrochim. Acta 1996, 41, 2267.

24. Hubbard, A.T.; Ishikawa, R.M.; Katekaru, J. J. Electroanal. Chem. 1978, 86, 289.

25. Gamboa-Aldeco, M.E.; Herrero, E.; Zelenay, P.; Wieckowski, A. J. Electroanal. Chem. 1993, 348, 451.

26. Markovic, N.; Marinkovic, N.; Adzic, R. J. Electroanal. Chem. 1988, 241, 309.

27. Woodward, F.E.; Scortichini, C.L.; Reilley, C.N. J. Electroanal. Chem. 1983, 151, 109.

28. Martins, M.E.; Salvarezza, R.C.; Arvia, A.J. J. Electrochem. Soc. 1991, 138, 2509.

29. Angerstein-Kozlowska, H. In A Comprehensive Treatise of Electrochemistry; Yeager, E.B.; Bockris, J.O’M.; Conway, B.E.; Sarangapani, S., Eds; Plenum Press, New York, 1984, Vol. 9, Chap. 2.

30. Petrii, O.A.; Vasina, S. Ya.; Luk'yanycheva, L.Yu. Elektrokhimiya 1981, 17, 1383.

31. Lezna, R.O.; Tacconi, N.R. de; Arvia, A.J. J. Electrochem. Soc. 1979, 126, 2140.

32. Gómez, R.; Clavilier, J. J. Electroanal. Chem. 1993, $354,189$.

33. Aberdam, D.; Durand, R.; Faure, R.; El Omar, F. Surf. Sci. 1986, 171, 303.

34. Matthews, D.B.; Bockris, J.O’M. In Modern Aspects of Electrochemistry; Bockris, J. O’M.; Conway, B.E., Eds; Academic Press, New York, 1971, Vol. 6, Chap. 4, p. 242.

35. Parsons, R.; Bockris, J.O’M. Trans. Faraday Soc. 1951, 47, 914.

36. Krishtalik, L.I. Electrode Reactions, in The Mechanism of the Elementary Act, Nauka, Moscow, 1979.

37. Kuznetsov, A.M. J. Electroanal. Chem. 1983, 159, 241.

38. Dogonadze, R.R.; Kuznetsov, A.M. Prog. Surf. Sci. 1975, $1,1$.

39. Kharkats, Yu I.; Ulstrup, J. J. Electroanal. Chem. 1975, 65, 555.

40. Wagner, F.T.; Moylan, T.E. Surf. Sci. 1987, 182, 125. 